CLINICAL STUDY

\title{
Medullary thyroid carcinoma identified within the first year of life in children with hereditary multiple endocrine neoplasia type $2 A(\operatorname{codon} 634)$ and $2 B$
}

D Zenaty, Y Aigrain ${ }^{1}$, M Peuchmaur $^{2}$, P Philippe-Chomette ${ }^{1}$, C Baumann ${ }^{3}$, F Cornelis $^{4}$, J P Hugot $^{5}$, D Chevenne $^{6}$ $V_{\text {Barbu }}{ }^{7}$, P J Guillausseau ${ }^{8}$, M Schlumberger ${ }^{9}$, J C Carel, J P Travagli ${ }^{10}$ and J Léger

Paediatric Endocrinology Department, Centre de Référence Maladies Endocriniennes Rares de la Croissance, ${ }^{1}$ Paediatric Surgery Department, ${ }^{2}$ Pathology Department, ${ }^{3}$ Medical Genetics Department, Assistance Publique-Hôpitaux de Paris, Robert Debré Hospital, Paris VII University, 48 Boulevard Sérurier, 75019 Paris, France and ${ }^{4}$ Medical Oncogenetic Department, Assistance Publique-Hôpitaux de Paris, Lariboisiere Hospital, Paris VII University, 75010 Paris, France, ${ }^{5}$ Paediatric Gastroenterology Department and ${ }^{6}$ Biochemistry Department, Assistance Publique-Hôpitaux de Paris, Robert Debré Hospital, Paris VII University, 75019 Paris, France, ${ }^{7}$ Biochemistry and Molecular Biology and Genetics Department, Assistance Publique-Hôpitaux de Paris, SaintAntoine Hospital, UPMC University Paris VI, 75012 Paris, France, ${ }^{8}$ Endocrinology Department, Assistance Publique-Hôpitaux de Paris, Lariboisiere Hospital, Paris VII University, 75010 Paris, France, ${ }^{9}$ Nuclear Medicine Department and ${ }^{10}$ Surgery Department, Gustave Roussy Institute and University Paris XI, 94800 Villejuif, France

(Correspondence should be addressed to J Léger; Email: juliane.leger@rdb.aphp.fr)

\begin{abstract}
Context: Early prophylactic thyroidectomy in patients with multiple endocrine neoplasia (MEN) type 2 offers the best chance for a normal life expectancy.

Objective: To analyze the results of thyroidectomy performed during the first year of life in six patients with MEN 2A (codon 634) or MEN 2B (codon 918) syndrome.

Design and setting: A university hospital-based prospective study from 2001 to 2008.

Subjects and methods: Six family members affected either by MEN 2A $(n=3)$ or MEN 2B $(n=3)$ syndrome were identified through neonatal genetic screening.

Results: Total thyroidectomy was performed at a median age of 0.8 year in the six patients, with central lymph node dissection in five. Bilateral millimetric medullary thyroid carcinoma (MTC) was found in all patients, with a unilateral lymph node micrometastasis in two of the three MEN 2B patients. Before thyroidectomy, MEN 2B patients had much higher basal serum calcitonin levels than those with MEN $2 \mathrm{~A}$ and controls. After thyroidectomy, with a median follow-up of 3.3 years, the six patients had no evidence of persistent MTC.

Conclusion: Bilateral millimetric MTC may be present during the first year of life in these patients, with lymph node metastases also occurring in MEN 2B patients. These results support a total thyroidectomy at the age of about one year in MEN 2A (codon 634) children with an abnormal serum calcitonin level, and a total thyroidectomy with central neck dissection within the first weeks of life in MEN 2B patients.
\end{abstract}

European Journal of Endocrinology 160 807-813

\section{Introduction}

Multiple endocrine neoplasia (MEN) type 2 is an autosomal dominant inherited syndrome caused by germ line mutations of the RET protooncogene and associated with a high penetrance of medullary thyroid carcinoma (MTC) (1-4). Surgery is the only curative treatment for MTC and should remove all neoplastic foci present in the neck (thyroid and lymph nodes) with an acceptable morbidity.

Three different syndromes can be distinguished: 1) MEN 2A, when MTC is associated with phaeochromocytoma and parathyroid adenoma; 2) MEN 2B, when MTC is associated with phaeochromocytoma, marfanoid habitus and intestinal ganglioneuromatosis and 3) familial MTC (FMTC), when only MTC is present (5-7).
Thyroidectomy at an early stage of the disease significantly improves long-term outcome in carriers of RET gene mutations. In such carriers, an agerelated progression has been documented from normal $\mathrm{C}$ cells, to premalignant $\mathrm{C}$ cell hyperplasia and finally to MTC. RET mutations have been shown to be closely associated with specific phenotypes, age of disease onset, and aggressiveness of the disease $(8-10)$. This has made it possible to assign three levels of risk to mutations $(4,9,11-13)$. The highest risk (level 3) is found in the rare MEN 2B patients, in whom MTC may occur before the age of 1 year (17), with metastatic disease observed in patients as young as 2.7 years (18). These patients should undergo total thyroidectomy with central neck dissection, during the first months of life. At risk level 2, subjects with 
mutations in exons 10 (codons 609, 611, 618, 620) and 11 (codon 634) should undergo total thyroidectomy before the age of 5 years $(9,12,15,16)$. At risk level 1 , with mutations in exons 13,14 or 15 (codons 609, 630, 768, 790, 791, 804, and 891), C cell disease may emerge later in life and thyroidectomy may be performed later in life, depending on calcitonin levels, neck ultrasound findings, family history and family preference (14).

Thyroid surgery and lymph node dissection during the first year of life may be difficult and may be associated with significant morbidity. No consensus has been reached regarding the need for prophylactic lymph node dissection in children with MEN 2A undergoing surgery before the age of 5 years. In a review of 42 MEN $2 \mathrm{~A}$ patients undergoing total thyroidectomy between the ages of 1 and 6 years, 5\% had normal histological results, $38 \%$ had diffuse $\mathrm{C}$ cell hyperplasia, and $57 \%$ had MTC, the youngest patient with MTC being one year old (codon 634 mutation), but no metastatic disease was observed $(19,20)$. In another study, only one of the 97 patients with an MTC measuring $1 \mathrm{~cm}$ or less, and a basal serum calcitonin concentration below $40 \mathrm{pg} / \mathrm{ml}$ had lymph node metastases (21). Therefore, as the benefits of prophylactic lymph node dissection remain unproven, its indication should be balanced against its risks. Lymph node dissection has been advocated in children with more extensive disease, as indicated by the presence of lymph node metastases on neck ultrasonography or on preoperative palpation, thyroid nodules greater than $5 \mathrm{~mm}$ in diameter or a basal serum calcitonin level $>40 \mathrm{pg} / \mathrm{ml}$ in a child over the age of 6 months $(14,22,23)$.

In this prospective single-centre study, the results of early thyroidectomy with central neck dissection, carried out during the first year of life in six subjects from MEN 2A and MEN 2B families were analyzed.

\section{Patients and methods}

Between 2001 and 2008, six subjects (two boys and four girls) belonging either to one MEN 2A family $(n=3)$ or one MEN 2B family $(n=3)$ were identified through familial screening during the neonatal period as carriers of RET gene mutations. The three children from the MEN 2A family had the Cys634Tyr substitution, and the three children from the MEN 2B family had the Met918Thr substitution.

Medical history was recorded and each subject also underwent physical examination, neck ultrasound examination, and determination of basal plasma calcitonin concentrations. Pentagastrin stimulation tests (slow i.v. injection of $0.5 \mathrm{~g} / \mathrm{kg}$ pentagastrin, with calcitonin measurement at $0,3,5$, and $10 \mathrm{~min}$ ) were carried out in five subjects. Plasma calcitonin concentration was determined by immunoradiometric assay (ELSA-hCT, CisBio International, Gif-sur-Yvette,
France), with the results interpreted according to normal values in childhood (24) and in control subjects $(n=23$, our unpublished data).

Surgery was performed by the same surgeons in each case, working as a surgical team (J P T, Y A, and P P C) (25). Total thyroidectomy was performed in the six patients with a central lymph node dissection (from the hyoid bone to the thoracic inlet and laterally to the carotid arteries), in the three MEN 2B patients and in two MEN 2A patients. Patient 4 also underwent bilateral level III and IV dissection. Patient 1 was the first young child with MEN 2A operated before the age of one year without central neck dissection. As bilateral MTC was found to our surprise in this MEN 2A patient, we decided to perform a lymph node level VI dissection in the two other MEN 2A patients. Thyroid surgery before the age of one year is subjected to certain constraints, such as the need to use magnifying glasses. Localization of the recurrent laryngeal nerve is straightforward in MEN 2B patients, in whom nerves are enlarged, but requires careful dissection in MEN 2A patients. The parathyroid glands, even for the superior ones are often hidden in or close to bulky thymus remnants; they are pale and difficult to distinguish from the thymus. They are sometimes nodular, with a fragile vasculature, and transplantation is difficult due to their small size. Methylene blue staining is ineffective at this age. Despite these difficulties, the parathyroid glands were identified in all patients and were autotransplanted into the sterno-cleido-mastoid muscle in four (patients 1, 3, 5, 6).

The characteristics of the tumour, including its location, size, uni- or multifocality and uni- or bilaterality, and the presence of lymph node metastases were evaluated by the same pathologist (MP). Thyroid specimens were fixed in neutral $3.7 \%$ formalin and each lobe was horizontally sectioned into slices 2 to $3 \mathrm{~mm}$ thick, from the upper to the lower pole, the isthmus being sectioned vertically. Lymph nodes were fixed in formalin and embedded in paraffin separately. All blocks were serially sectioned and stained with haematin-eosin. Immunohistochemistry was carried out with antibodies directed against calcitonin. Negative control consisted in the omission of the first antibody. C cell hyperplasia was defined as the presence of 5-20 calcitonin-immunoreactive cells within or between the thyroid follicles, and displaying no architectural disorganization.

Serum concentrations of calcitonin, thyroid hormones, calcium, and parathyroid hormone were checked after surgery and every 3-6 months during follow-up. Postoperative L-thyroxin treatment was administered to all children, with calcium and vitamin D supplementation when appropriate.

This study was approved by the local ethics committee and informed consent was obtained from the parents. 


\section{Statistical analysis}

Results are expressed as medians with ranges, or 25-75th percentiles. The Mann-Whitney $U$ test was performed for comparison between groups.

\section{Results}

As shown in Fig. 1, pre-operative basal and pentagastrin-stimulated calcitonin levels were significantly higher in MEN 2B patients than in MEN 2A patients $(P=0.009)$, with median basal calcitonin levels (25-75th percentile) at $345 \mathrm{ng} / \mathrm{ml}$ (321-440) and $32 \mathrm{ng} / \mathrm{ml}$ (30-37) respectively. All MEN 2A children $(n=3)$ had basal serum calcitonin levels higher than those found in control children of similar age, for whom levels are below $20 \mathrm{ng} / \mathrm{ml}$ after 3 months of age.

Surgery was performed between the ages of 3 and 12 months in the six patients. It consisted in a total thyroidectomy in the six patients with a central lymph node dissection in five (Table 1).

\section{The MEN 2A family (codon 634)}

The three patients studied belonged to the same affected family. The two mothers of these three children were sisters and had undergone total thyroidectomy at the ages of 12 and 14 years respectively. Both sisters were found to have MTC without lymph node metastases. Bilateral adrenalectomy was performed for phaeochromocytoma in both these women during their twenties and one of them also developed hyperparathyroidism.

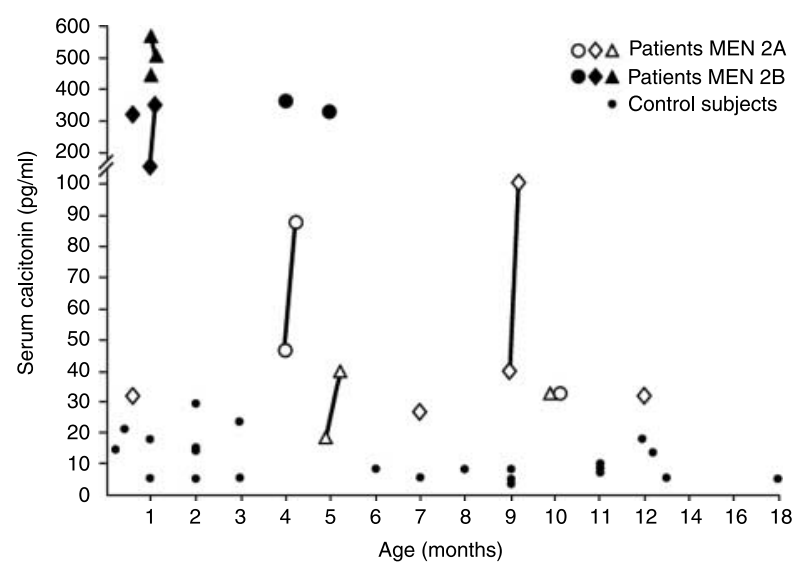

Figure 1 Basal and pentagastrin-stimulated serum calcitonin levels during the first months of life, before thyroidectomy, in the six patients with either MEN 2A (codon 634 mutation; $n=3$; open symbols) or MEN 2B codon 918 ( $n=3$, dark symbols) syndrome. Higher preoperative calcitonin levels were found in MEN 2B patients compared with MEN 2A patients. Basal serum calcitonin levels were below the detection threshold after thyroidectomy in all six patients, with a present median follow-up of 3.3 years (0.7-6.3 years). Healthy children with normal values are represented by dots.
The three children presented no abnormality on physical examination and neck ultrasound examination. Thyroidectomy with central neck dissection was performed at the ages of 10 and 12 months in two children (patients 2 and 3 ) and at the age of 10 months in the remaining child, who did not undergo central neck dissection (patient 1). Bilateral MTC was found in all three cases, with tumoral nodules of $1-2.5 \mathrm{~mm}$ in diameter. Bilateral $C$ cell hyperplasia was found in two children (patients 1 and 2), but not in patient 3 . No lymph node metastases were detected.

\section{The MEN 2B family}

The mother had a typical MEN 2B syndrome and underwent total thyroidectomy and external radiation therapy of the neck at the age of 6 years, followed by partial colectomy for intestinal ganglioneuromatosis at the age of eight years. She became pregnant for the first time at the age of 26 . After uneven pregnancies and deliveries, the three children were found to have dysmorphic features typical of MEN 2B syndrome, with marfanoid habitus and neonatal clinical manifestations of intestinal ganglioneuromatosis with intestinal pseudo-obstruction syndrome. Unilateral pyelic duplication was also observed in one child (patient 6).

No thyroid abnormality was found on ultrasound examination in two sisters (patients 4 and 5). The third sister (patient 6), who had the highest basal calcitonin level at $568 \mathrm{ng} / \mathrm{ml}$ at one month, with no increase following pentagastrin stimulation, was found to have two small hypoechogenic and vascularised nodules of $4 \mathrm{~mm}$ in diameter at the upper pole of each thyroid lobe on ultrasound examination.

As indicated in Table 1, total thyroidectomy with central lymph node dissection was performed at the age of three months in two sisters (patient 5 and 6) and at 12 months in one sister (patient 4). A bilateral level III and IV lymph node dissection was also performed in one patient (patient 4). On histological examination, bilateral MTC, with tumoural nodules of $2-4 \mathrm{~mm}$ in diameter in each lobe, was found in all three girls (Fig. 2a-c). In all three cases, one or several foci of $\mathrm{C}$ cell hyperplasia (unilateral $n=2$, bilateral $n=1$ ) were detected by immunohistochemistry (Fig. 2d). A single paratracheal (level VI) lymph node metastasis (isolated intrasinusal synaptophysin/chromogranin-immunoreactive cells) was found in patient 6 who underwent surgery at the age of three months and in patient 4 who underwent surgery at the age of 12 months (patient 4; Fig. 3a and b).

\section{Follow-up}

Median follow-up after surgery was 3.3 years (range from 0.7 to 6.3 years). At the last evaluation, the median age of the patients was 4.2 years (range: $1.8-7.3$ years) 


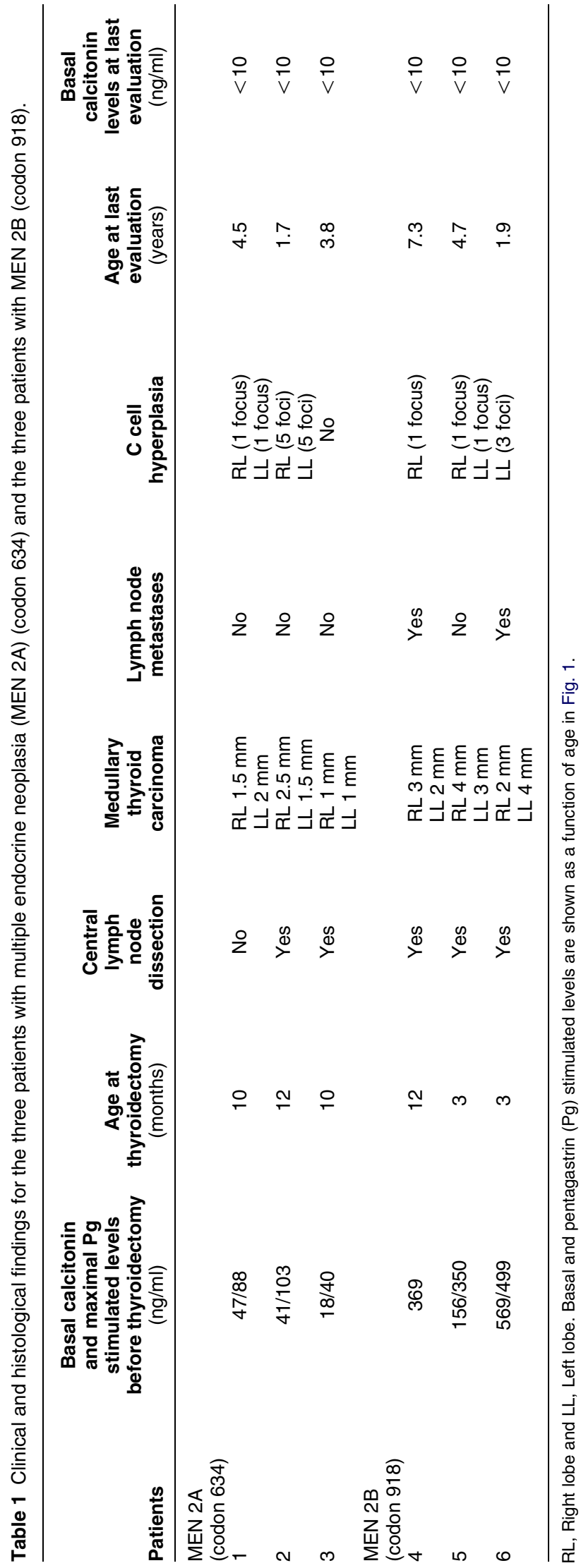

and all patients had basal serum calcitonin levels below the detection threshold (Table 1).

At this young age, none of the children displayed any evidence of phaeochromocytoma (normal metanephrine levels) and none of the three children with MEN 2A displayed any evidence of hyperparathyroidism.

No laryngeal nerve paralysis was observed, but definitive hypoparathyroidism occurred in one MEN $2 \mathrm{~A}$ child (patient 1), in whom two parathyroid glands were included within the thyroid gland and one parathyroid gland was damaged during intraoperative frozen section analysis before autotransplantation; of interest, patient 1 did not undergo lymph node dissection.

\section{Discussion}

In MEN 2 mutation carriers, the timing of thyroidectomy depend on the type of RET mutation and on the earliest observed occurrence of MTC in patients with the mutation. In this study, six gene carriers were identified through familial screening, and thyroidectomy was performed during the first year of life. Bilateral microscopic MTC was found in all six patients and $\mathrm{C}$ cell hyperplasia, in five. Furthermore, unilateral paratracheal (level VI) lymph node metastases, consisting of a few cells detected by immunohistochemistry were found in two MEN 2B children undergoing surgery at 3 and 12 months of life. MTC thus occurred earlier than previously reported in these patients $(9,12,15-20$, 26-28). Our findings therefore justify a thyroidectomy as early as one year of age in MEN 2A children with a RET gene mutation at codon 634 with abnormal serum calcitonin levels, and as soon as possible in those with MEN 2B syndrome. In our patients with MEN 2B, basal calcitonin levels were particularly high, indicating extensive disease and suggesting that surgery should include thyroidectomy and central neck dissection. Owing to the potential morbidity with definitive hypoparathyroidism risk associated with lymph node dissection, the use of this procedure in young MEN 2A patients with codon 634 mutation remains controversial $(9,25)$. Of note, the only patient who had a permanent hypoparathyroidism did not undergo lymph node dissection, underlying a risk due to anatomical variation that is difficult to avoid.

The identification of recurrent nerves and parathyroid glands is challenging in very young children, and requires experienced surgeons. No laryngeal nerve paralysis was observed in our patients. Total thyroidectomy and complete central and lateral lymph node dissection is the most complete preventive surgical approach. It removes potential micrometastases in the central and lateral lymph node compartment. However, because of the morbidity related to complete neck dissection, it does not routinely apply to very young MEN 2A subjects (25). None of our three patients with a 

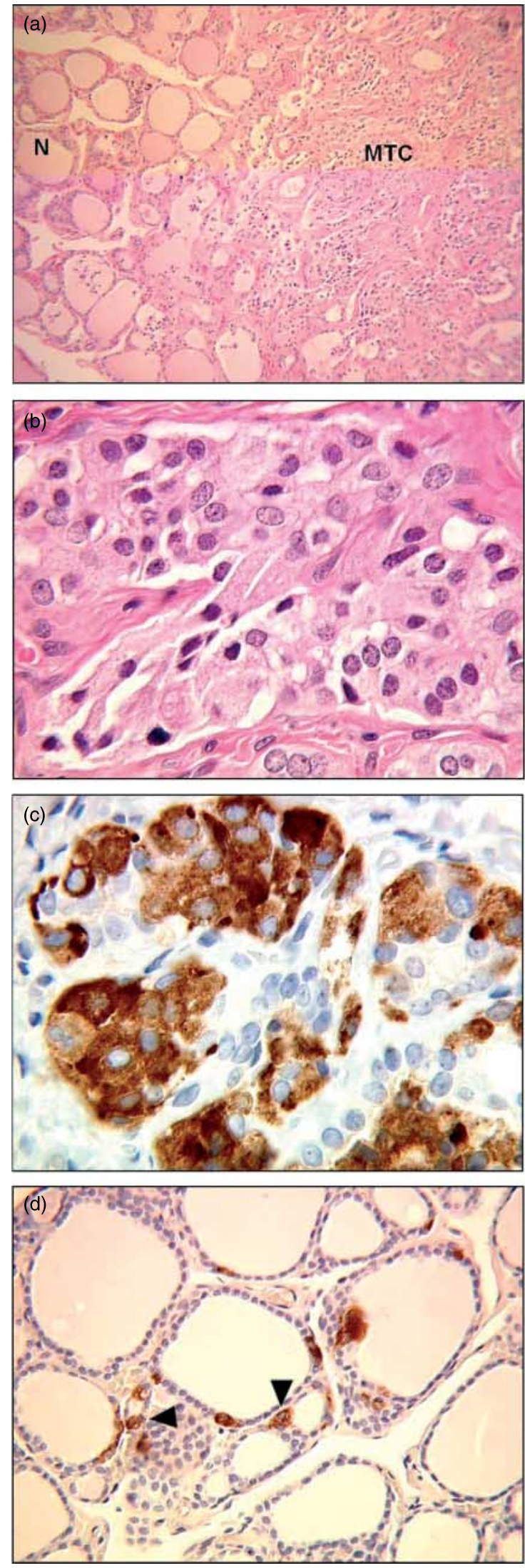

codon 634 mutation had lymph node metastases, consistent with the rarity of lymph node metastases before the age of 10 years $(11,23,29)$. Indeed, lymph node metastases are uncommon in patients with thyroid tumour foci less than $5 \mathrm{~mm}$ in diameter and with basal calcitonin levels below $40 \mathrm{pg} / \mathrm{ml}(14,22,23)$. Finally, the mean interval between the onset of MTC and the presence of lymph node metastases has been estimated at 6.6 years for carriers of codon 634 mutations (11). However, nucleotide and aminoacid exchange with specific changes in cysteine substitution might also have a direct impact on tumour aggressiveness in MEN 2A syndrome with codon 634 mutation (30).

Performing surgery at a young age should avoid central neck dissection in MEN 2A patients, even if small neoplastic foci are found in the thyroid gland. It has been shown that the risk of lymph node metastases increases with serum calcitonin levels (31) and with the size and multifocality of MTC (32), as shown by the presence in our study, of bilateral millimetric MTC and metastatic lymph node at 3 and 12 months of age in children with MEN 2B and high serum calcitonin levels before surgery. Machens et al. recently demonstrated the existence of a strong dose-dependence relationship between preoperative calcitonin levels after pentagastrin stimulation (less than 10-fold increase in calcitonin preoperative levels) and the frequency and number of lymph node metastases in patients with untreated MTC (33), but this relationship may not apply to patients with micrometastases only, such as our two MEN 2B patients.

Our three MEN 2A patients with codon 634 mutation had higher basal calcitonin levels than our control population. It should be stressed that it is very difficult to interpret basal and stimulated calcitonin levels at this age, because apart from our data obtained in a small number of children, no reference values are available for healthy children under the age of one year. Our three MEN 2B children had basal serum calcitonin levels significantly higher than MEN 2A children, indicating more extensive disease. In this respect, the pentagastrin test provided no further information, and is therefore probably unnecessary in such children.

Detectable serum concentrations of calcitonin during the follow-up of patients after total thyroidectomy are indicative of residual or recurrent disease $(22,34)$. In our study, with a median follow-up of 3.3 years after thyroidectomy, serum calcitonin levels remained undetectable in the six patients.

Figure 2 Histological data for a thyroid specimen showing medullary thyroid carcinoma (MTC) and C cell hyperplasia, from one patient with MEN 2B. (a) Microscopic section with haematineosin staining; MTC: medullary thyroid carcinoma without capsule; $\mathrm{N}$ : normal thyroid tissue (original magnification $\times 160$ ). (b) MTC with polygonal tumour cells arranged in solid sheets in a fibrous stroma (original magnification $\times 1000$ ). (c) Tumour cells immunostained with anti-synaptophysin antibodies (original magnification $\times 1000$ ). (d) C cell hyperplasia detected by immunohistochemical staining with anti-chromogranin antibodies (arrowhead) (original magnification $\times 400$ ). 

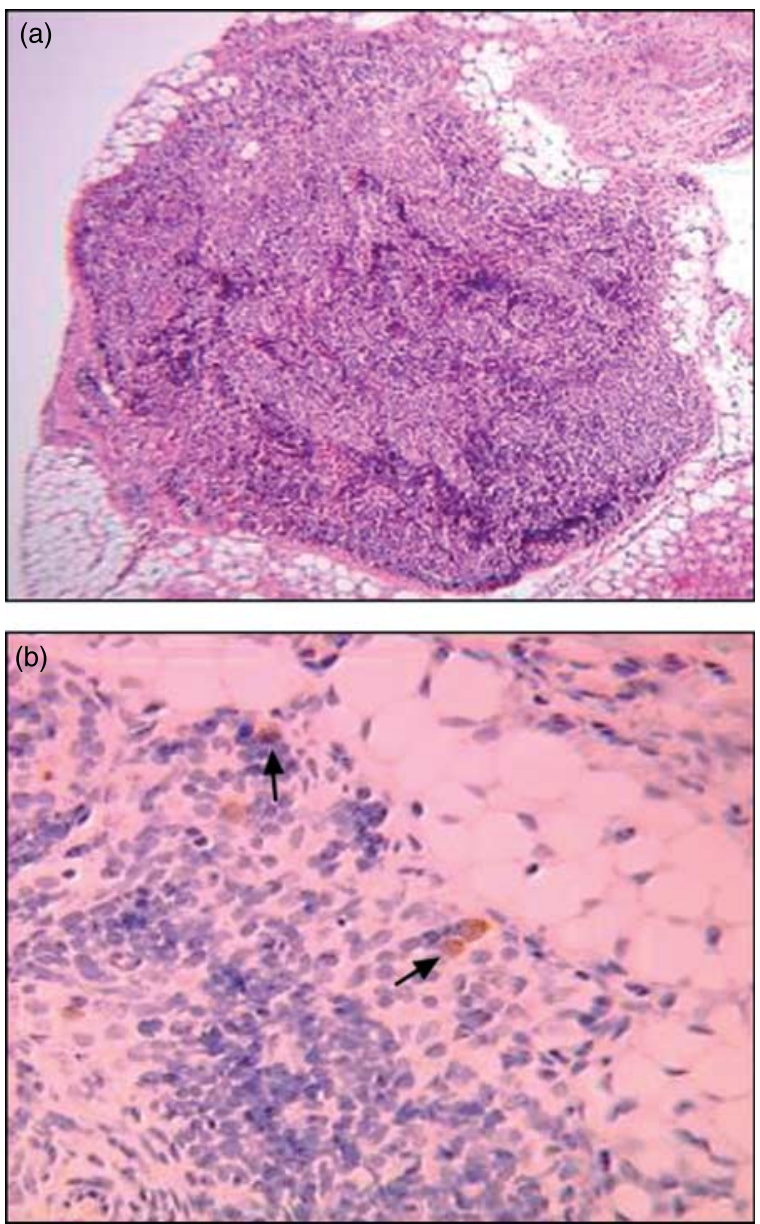

Figure 3 Histological data for a lymph node specimen from a MEN 2B patient. (a) Microscopic section from a right paratracheal lymph node, stained with hematoxylin and eosin (original magnification $\times 160$ ). (b) Immunostaining for synaptophysin, showing a few isolated intrasinusal immunoreactive cells (black arrow) (original magnification $\times 400$ ).

Evidence is accumulating to suggest that long-term outcome after thyroidectomy in asymptomatic RET mutation carriers is better if surgery is carried out at a young age (35). A meta-analysis comparing the disease stage and outcome after thyroidectomy in MEN 2A patients showed significantly lower rates of invasive and metastatic MTC and of persistent or recurrent disease in patients undergoing surgery before the age of six years than in those undergoing surgery between the ages of 6 and 20 years. The follow-up of 50 asymptomatic children who underwent thyroidectomy showed in 44 patients normal basal and pentagastrin-stimulated calcitonin levels at least five years after surgery (12). However, the rarity of MEN 2B patients has precluded the evaluation of long-term prognosis for this condition, as too few patients have been studied (27).

In conclusion, our study reports the detection of MTC on thyroidectomy in three MEN 2A (codon 634) and three MEN 2B patients, with lymph node micrometastases in two MEN 2B patients as young as three months of age. This justifies total thyroidectomy with central neck dissection as soon as possible in MEN $2 \mathrm{~B}$ subjects, and the presence of MTC in the three MEN 2A children also suggests that thyroidectomy should be performed at the age of about one year in children with MEN 2A (codon 634) with abnormal serum calcitonin levels. Central lymph node dissection should be performed, along with thyroidectomy, in MEN 2B children with high serum calcitonin levels. Long-term follow-up is required to determine whether very early thyroidectomy improves the long-term outcome of these patients. This study also demonstrates that the pentagastrin stimulation test is of limited value in these young children. Finally, despite the clear genotype-phenotype correlation in MEN 2, with thyroidectomy presently being the only effective curative or preventive treatment, the psychological implications of this treatment modality should be investigated when assessing individuals at risk.

\section{Declaration of interest}

The authors declare that there is no conflict of interest that could be perceived as prejudicing the impartiality of the research reported.

\section{Funding}

This research did not receive any specific grant from any funding agency in the public, commercial or not-for-profit sector.

\section{References}

1 Mulligan LM, Kwok JB, Healey CS, Elsdon MJ, Eng C, Gardner E, Love DR, Mole SE, Moore JK, Papi L, Ponder MA, Telenius H, Tunnacliffe A \& Ponder BAJ. Germ-line mutations of the RET proto-oncogene in multiple endocrine neoplasia type 2A. Nature $1993363458-460$.

2 Hofstra RM, Landsvater RM, Ceccherini I, Stulp RP, Stelwagen T, Luo Y, Pasini B, Hoppener JW, van Amstel HK, Romeo G, Lips CJM \& Buys CHCM. A mutation in the RET proto-oncogene associated with multiple endocrine neoplasia type $2 \mathrm{~B}$ and sporadic medullary thyroid carcinoma. Nature 1994367 375-376.

3 Santoro M, Carlomagno F, Romano A, Bottaro DP, Dathan NA, Grieco M, Fusco A, Vecchio G, Matoskova B \& Kraus MH. Activation of RET as a dominant transforming gene by germline mutations of MEN2A and MEN2B. Science 1995267 381-383.

4 Wolfe HJ, Melvin KE, Cervi-Skinner SJ, Saadi AA, Juliar JF, Jackson CE \& Tashjian AH Jr. C-cell hyperplasia preceding medullary thyroid carcinoma. New England Journal of Medicine 1973289 437-441.

5 Cunliffe WJ, Hudgson P, Fulthorpe JJ, Black MM, Hall R, Johnston ID \& Shuster S. A calcitonin-secreting medullary thyroid carcinoma associated with mucosal neuromas, marfanoid features, myopathy and pigmentation. American Journal of Medicine 197048 120-126.

6 Keiser HR, Beaven MA, Doppman J, Wells S Jr \& Buja LM. Sipple's syndrome: medullary thyroid carcinoma, pheochromocytoma, and parathyroid disease. Studies in a large family. NIH conference. Annals of Internal Medicine $1973 \mathbf{7 8}$ 561-579.

7 Farndon JR, Leight GS, Dilley WG, Baylin SB, Smallridge RC, Harrison TS \& Wells SA Jr. Familial medullary thyroid carcinoma without associated endocrinopathies: a distinct clinical entity. British Journal of Surgery 198673 278-281. 
8 Eng C, Clayton D, Schuffenecker I, Lenoir G, Cote G, Gagel RF, van Amstel HK, Lips CJ, Nishisho I, Takai SI, Marsh DJ, Robinson BG, Frank-Raue K, Raue F, Xue F, Noll WW, Romei C, Pacini F, Fink M, Niederle B, Zedenius J, Nordenskjold M, Komminoth P, Hendy GN \& Mulligan LM. The relationship between specific RET protooncogene mutations and disease phenotype in multiple endocrine neoplasia type 2. International RET mutation consortium analysis. Journal of the American Medical Association 1996276 1575-1579.

9 Brandi ML, Gagel RF, Angeli A, Bilezikian JP, Beck-Peccoz P, Bordi C, Conte-Devolx B, Falchetti A, Gheri RG, Libroia A, Lips CJ, Lombardi G, Mannelli M, Pacini F, Ponder BA, Raue F, Skogseid B, Tamburrano G, Thakker RV, Thompson NW, Tomassetti P, Tonelli F, Wells SA Jr \& Marx SJ. Guidelines for diagnosis and therapy of MEN type 1 and type 2. Journal of Clinical Endocrinology and Metabolism 200186 5658-5671.

10 Niccoli-Sire P, Murat A, Rohmer V, Franc S, Chabrier G, Baldet L, Maes B, Savagner F, Giraud S, Bezieau S, Kottler ML, Morange S \& Conte-Devolx B. Familial medullary thyroid carcinoma with noncysteine ret mutations: phenotype-genotype relationship in a large series of patients. Journal of Clinical Endocrinology and Metabolism 200186 3746-3753.

11 Machens A, Niccoli-Sire P, Hoegel J, Frank-Raue K, van Vroonhoven TJ, Roeher HD, Wahl RA, Lamesch P, Raue F, Conte-Devolx B \& Dralle H. Early malignant progression of hereditary medullary thyroid cancer. New England Journal of Medicine 2003349 1517-1525.

12 Skinner MA, Moley JA, Dilley WG, Owzar K, Debenedetti MK \& Wells SA Jr. Prophylactic thyroidectomy in multiple endocrine neoplasia type 2A. New England Journal of Medicine 2005353 $1105-1113$.

13 De Groot JW, Links TP, Plukker JT, Lips CJ \& Hofstra RM. RET as a diagnostic and therapeutic target in sporadic and hereditary endocrine tumors. Endocrine Reviews 200627 535-560.

14 Niccoli-Sire P, Murat A, Rohmer V, Gibelin H, Chabrier G, Conte-Devolx B, Visset J, Ronceray J, Jaeck D, Henry JF, Proye C, Carnaille B \& Kraimps JL. When should thyroidectomy be performed in familial medullary thyroid carcinoma gene carriers with non-cysteine RET mutations? Surgery 2003134 1029-1036.

15 Kahraman T, de Groot JW, Rouwe C, Hofstra RM, Links TP, Sijmons RH \& Plukker JT. Acceptable age for prophylactic surgery in children with multiple endocrine neoplasia type 2a. European Journal of Surgical Oncology 200329 331-335.

16 Piolat C, Dyon JF, Sturm N, Pinson S, Bost M, Jouk PS, Plantaz D \& Chabre O. Very early prophylactic thyroid surgery for infants with a mutation of the RET proto-oncogene at codon 634: evaluation of the implementation of international guidelines for MEN type 2 in a single centre. Clinical Endocrinology 200665 118-124.

17 Unruh A, Fitze G, Janig U, Bielack S, Lochbuhler H \& Coerdt W. Medullary thyroid carcinoma in a 2-month-old male with multiple endocrine neoplasia $2 \mathrm{~B}$ and symptoms of pseudoHirschsprung disease: a case report. Journal of Pediatric Surgery 200742 1623-1626.

18 Leboulleux S, Travagli JP, Caillou B, Laplanche A, Bidart JM, Schlumberger M \& Baudin E. Medullary thyroid carcinoma as part of a multiple endocrine neoplasia type 2B syndrome: influence of the stage on the clinical course. Cancer 200294 44-50.

19 Modigliani E, Cohen R, Campos JM, Conte-Devolx B, Maes B, Boneu A, Schlumberger M, Bigorgne JC, Dumontier P, Leclerc L, Corcuff B \& Guilhem I. Prognostic factors for survival and for biochemical cure in medullary thyroid carcinoma: results in 899 patients. The GETC study group. Clinical Endocrinology $2003 \mathbf{4 8}$ 265-273.

20 Szinnai G, Meier C, Komminoth P \& Zumsteg UW. Review of multiple endocrine neoplasia type $2 \mathrm{~A}$ in children: therapeutic results of early thyroidectomy and prognostic value of codon analysis. Pediatrics 2003111 132-139.
21 Scheuba C, Kaserer K, Bieglmayer C, Asari R, Riss P, Drosten R \& Niederle B. Medullary thyroid microcarcinoma recommendations for treatment-a single-center experience. Surgery $2007 \mathbf{1 4 2}$ 1003-1010.

22 Machens A, Schneyer U, Holzhausen HJ \& Dralle H. Prospects of remission in medullary thyroid carcinoma according to basal calcitonin level. Journal of Clinical Endocrinology and Metabolism $2005902029-2034$.

23 Frank-Raue K, Buhr H, Dralle H, Klar E, Senninger N, Weber T, Rondot S, Hoppner W \& Raue F. Long-term outcome in 46 gene carriers of hereditary medullary thyroid carcinoma after prophylactic thyroidectomy: impact of individual RET genotype. European Journal of Endocrinology 2006155 229-236.

24 Verga U, Morpurgo PS, Vaghi I, Radetti G \& Beck-Peccoz P. Normal range of calcitonin in children measured by a chemiluminescent two-site immunometric assay. Hormone Research 200666 17-20.

25 Scollo C, Baudin E, Travagli JP, Caillou B, Bellon N, Leboulleux S \& Schlumberger M. Rationale for central and bilateral lymph node dissection in sporadic and hereditary medullary thyroid cancer. Journal of Clinical Endocrinology and Metabolism $2003 \mathbf{8 8}$ 2070-2075.

26 Sanso GE, Domene HM, Garcia R, Pusiol E, de M, Roque M, Ring A, Perinetti H, Elsner B, Iorcansky S \& Barontini M. Very early detection of RET proto-oncogene mutation is crucial for preventive thyroidectomy in multiple endocrine neoplasia type 2 children: presence of C-cell malignant disease in asymptomatic carriers. Cancer 200294 323-330.

27 Brauckhoff M, Gimm O, Weiss CL, Ukkat J, Sekulla C, Brauckhoff K, Thanh PN \& Dralle H. Multiple endocrine neoplasia 2B syndrome due to codon 918 mutation: clinical manifestation and course in early and late onset disease. World Journal of Surgery 200428 1305-1311.

28 Jackson MB, Guttenberg M, Hedrick H \& Moshang T Jr. Multiple endocrine neoplasia type $2 \mathrm{~A}$ in a kindred with $\mathrm{C} 634 \mathrm{Y}$ mutation. Pediatrics $2005116468-471$.

29 Machens A, Ukkat J, Brauckhoff M, Gimm O \& Dralle H. Advances in the management of hereditary medullary thyroid cancer. Journal of Internal Medicine 2005257 50-59.

30 Punales MK, Graf H, Gross JL \& Maia AL. RET codon 634 mutations in multiple endocrine neoplasia type 2: variable clinical features and clinical outcome. Journal of Clinical Endocrinology and Metabolism 200388 2644-2649.

31 Baudin E, Travagli JP \& Schlumberger M. How effective is prophylactic thyroidectomy in asymptomatic multiple endocrine neoplasia type 2A? Nature Clinical Practice. Endocrinology and Metabolism 20062 256-257.

32 Machens A, Hauptmann S \& Dralle H. Increased risk of lymph node metastasis in multifocal hereditary and sporadic medullary thyroid cancer. World Journal of Surgery 200731 1960-1965.

33 Machens A, Hauptmann S \& Dralle H. Medullary thyroid cancer responsiveness to pentagastrin stimulation: an early surrogate parameter of tumor dissemination? Journal of Clinical Endocrinology and Metabolism 200893 2234-2238.

34 Niccoli P, Wion-Barbot N, Caron P, Henry JF, de Micco C, Saint Andre JP, Bigorgne JC, Modigliani E \& Conte-Devolx B. Interest of routine measurement of serum calcitonin: study in a large series of thyroidectomized patients. The French Medullary Study Group. Journal of Clinical Endocrinology and Metabolism 199782 338-341.

35 Machens A, Hofmann C, Hauptmann S \& Dralle H. Locoregional recurrence and death from medullary thyroid carcinoma in a contemporaneous series: 5-year results. European Journal of Endocrinology 2007157 85-93.

Received 19 January 2009

Accepted 13 February 2009 